\title{
Radiofrequency ablation of focal atrial tachycardia: Benefit of electroanatomical mapping over conventional mapping
}

\author{
N Szegedi ${ }^{1}$, E Zima ${ }^{1}$, M Clemens ${ }^{3}$, A Szekely ${ }^{2}$, RG Kiss², G Szeplaki ${ }^{1}$, L Geller ${ }^{1}$, \\ B Merkely ${ }^{1}$, Z Csanadi $^{3}$, G Duray $^{2}$ \\ ${ }^{1}$ Heart and Vascular Center, Semmelweis University, Budapest, Hungary \\ ${ }^{2}$ Department of Cardiology, State Health Center, Budapest, Hungary \\ ${ }^{3}$ Cardiology Institute, University of Debrecen, Debrecen, Hungary
}

Received: July 15, 2014

Accepted after revision: May 26, 2015

\begin{abstract}
Background: Catheter ablation is a proven therapy of focal atrial tachycardia. However limited information is available about the additional value of electroanatomical over conventional mapping methods for this specific arrhythmia. Methods: Consecutive catheter ablation procedures of FAT were analyzed in two cardiology centres. Only conventional mapping was used in 30 of the 60 procedures whereas additionally CARTO mapping was performed in another 30 procedures. Acute, six-month success rate, and procedural data were analyzed. Results: Localization of ectopic foci is congruent with previously published data. There was no statistically significant difference between procedure time and fluoroscopy time using additionally CARTO mapping, compared to conventional mapping only. Acute success rate was higher in procedures guided by CARTO mapping than in procedures based on conventional mapping $(27 / 30$ vs. $18 / 30, p=0.0081)$. During the 6 -month follow-up period there was a better outcome $(p=0.045)$ in case of CARTO guided procedures (success: 11 cases, partial success: 12 cases, failure: 4 cases) compared to conventional mapping (success: 4 cases, partial success: 18 cases, failure: 7 cases). Conclusions: Catheter ablation of focal atrial tachycardias using the CARTO electroanatomical mapping system seems to provide higher acute and 6-month success rate compared to ablation using conventional mapping methods only.
\end{abstract}

Keywords: focal atrial tachycardia, catheter ablation, CARTO, electroanatomical mapping, conventional mapping

Symptomatic focal atrial tachycardia (FAT) is relatively rare; it occurs in about $0.46 \%$ of the population (19). FAT accounts for 10 to $15 \%$ of patients referred for catheter ablation of supraventricular tachycardia (SVT) $(3,4,10,22,26)$, with a higher incidence (10 to $23 \%)$ in children especially when associated with congenital heart disease $(28,30)$. The prognosis of patients with FAT is usually benign with the exception of incessant forms, which may lead to tachycardia-induced cardiomyopathy $(5,28,30)$.

FATs have characteristic anatomical localizations, which has been reported in details previously $(2,6,16,24,31)$. The majority of FATs originate from the right atrium, especially from the crista terminalis (13) and coronary sinus (3). Although there are some algorithms to predict the site of origin of FAT using the P wave morphology of the surface ECG $(11,20$, $24,27)$, the precise localization of the ectopic foci remains often difficult with 12-lead ECG.

Corresponding author: Gabor Duray $\mathrm{MD}, \mathrm{PhD}$

Department of Cardiology of State Health Center

Róbert Károly Krt. 44, H-1134 Budapest, Hungary

Phone: +36-30-360-3623; Fax: +36-1-465-1857; E-mail: gduray@yahoo.com 
No large studies have been conducted to assess the effect of pharmacologic treatment on patients with focal ATs, but both paroxysmal and incessant ATs are reported to be difficult to treat medically $(23,24)$. Interventional therapy is reported as the best and safest therapy for patients with drug-refractory AT or incessant AT, especially when tachycardia-induced cardiomyopathy has been developed $(5,9,23,24,30)$. Catheter ablation is now accepted as the treatment of choice for this type of tachycardia, the success rate varies between 70 and $100 \%(1,3,10,13-16,18,21,23,25,29,30)$.

Conventional mapping and CARTO electroanatomical mapping are complementary during electrophysiological study and catheter ablation. The aim of our study was to evaluate the clinical benefit of CARTO electroanatomical mapping system used for ablation of focal atrial tachycardias over conventional mapping methods. Acute and six-month success rate of FAT ablation as well as procedural data were evaluated in cases performed using conventional mapping methods only and in cases with additional mapping using the CARTO system.

To the best of our knowledge there are no comparative data available evaluating the additional clinical value of electroanatomical mapping over conventional mapping in a consecutive dataset of patients who underwent catheter ablation of focal atrial tachycardia.

\section{Materials and Methods}

\section{Patients}

Data of consecutive patients underwent catheter ablation of incessant or paroxysmal FAT were collected retrospectively in two Hungarian cardiology centres: Cardiology Institute of University of Debrecen, Debrecen, Hungary (between 2006 and 2011), and Department of Cardiology of Military Hospital, State Health Center, Budapest, Hungary (between 2009 and 2011).

\section{EP study}

The electrophysiology study and catheter ablation procedure was explained to all patients and written informed consent was obtained from all of them before the study. Possible reversible causes were corrected in all patients. All antiarrhythmic drugs were ceased a minimum of five half-lives before the procedure.

The electrophysiological study was performed using quadripolar electrode catheters positioned in the high right atrium, His-bundle region, and right ventricular apex and a decapolar electrode catheter positioned in the coronary sinus. A steerable ablation catheter was inserted through the right femoral vein for atrial mapping, pacing, and ablation. After the atrial tachycardia has been verified using conventional criteria (12) the tachycardia mechanism was studied as well, and was considered microreentrant if it could be induced by programmed atrial stimulation, and automatic if it was induced by an infusion of isoproterenol and triggered activity if it could be induced by burst pacing. The same induction method was used after catheter ablation to prove the effect of the lesions.

Mapping of the atrial tachycardia was performed during ongoing atrial tachycardia using the already inserted diagnostic and additional deca- or duodecapolar mapping catheters according to the operating physician's preference. Additionally or alternatively to multipolar catheter mapping electroanatomical mapping (CARTO) system was selected by the operating physician based on individual decision. Aim of the mapping was to localize the earliest endocardial potential preceeding the onset of the surface P-wave. 
System components and technical principles of electroanatomical mapping (CARTO XP V9.6 system and Navistar catheter family, Biosense Webster, Inc., Diamond Bar, CA, USA) have been previously described in detail $(7,10,16,17)$. Electroanatomical mapping was performed during ongoing tachycardia as well, and area of earliest activation with respect to the reference electrogram was determined based on three dimensional activation maps (Fig. 1).

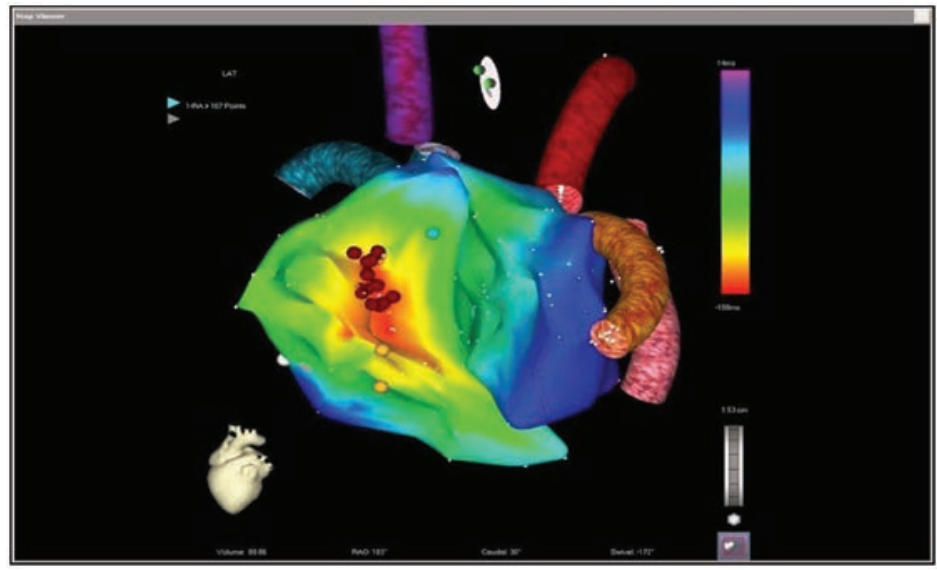

Fig. 1. Activation map of a right anteroseptal focal atrial tachycardia

Radiofrequency ablation was performed at the site of earliest atrial activation with the same catheter used for mapping. Selection of non-irrigated (with $4 \mathrm{~mm}$ tip) or irrigated tip catheter was based on the operating physician's preference. RF applications were performed during continuous impedance and temperature monitoring. The radiofrequency energy was applied in unipolar pulses directed from the catheter tip to an electrode placed in the dorsal region. The pre-defined temperature was $60^{\circ} \mathrm{C}$ in cases ablated with non-irrigated catheter and $41{ }^{\circ} \mathrm{C}$ in cases ablated with irrigated catheter. Radiofrequency energy was started at 20 $\mathrm{W}$ and increased up to $30 \mathrm{~W}$ to reach the target temperature and maximum duration was 60 seconds in all cases.

All the previously mentioned catheters and techniques were available in the two centres throughout the investigated time period ensuring the maximal flexibility for choosing the mapping strategy.

\section{Success definition}

Acute success was defined as absence and non-inducibility of the FAT by programmed extrastimuli, burst atrial pacing and/or isoproterenol administration according to the previously clarified mechanism and effective induction methods. The procedure was categorized as successful if the tachycardia remained not inducible even at least 30 minutes after the last radiofrequency application. Acute failure of the ablation was considered if shorter tachycardia episodes remained still inducible, or the duration and/or inducibility of FAT episodes decreased, or the applications did not terminate the tachycardia and it remained inducible.

At 6 months after discharge, patients were assessed in out-patient consultations, and underwent 12-lead ECG and Holter-monitoring. Success was defined as no recurrence of FAT episodes without any antiarrhythmic drug therapy during the six-month follow-up. 
Partial success was defined in case of asymptomatic tachycardia recurrences on $24 \mathrm{~h}$ Holter monitoring or ECG recordings, or in cases when symptoms regressed on antiarrhythmic drug therapy. Failure was defined as the persistence of symptoms either with or without antiarrhythmic therapy.

\section{Statistical analysis}

Continuous variables are expressed as mean \pm standard deviation (SD). Comparisons between groups were performed with $\mathrm{Chi}^{2}$ for trend test in case of acute and 6-month success analysis. A $p$ value less than 0.05 was considered statistically significant.

\section{Results}

Present study comprised 60 procedures ( 6 repeated ablations) of 54 consecutive patients (39 females, age $54 \pm 17$ years).

Baseline parameters did not differ in the two patient populations (Table I). Fifty patients were on antiarrhythmic drugs before the procedure. None of the patients developed cardiomyopathy. We noticed hypertension in 21 cases, 5 patients had COPD, 10 patients had ischaemic heart disease, 16 of them had other supraventricular arrhythmia as well and 5 of them underwent heart surgery earlier.

\section{Localization of ectopic foci}

We found 46 right-sided foci: 14 coronary sinus (CS), 11 crista terminalis $(\mathrm{Cr}), 7$ superior vena cava (SVC), 3 parahisian (His), 2 septal, 3 tricuspid annulus, 1 inferior vena cava, 5 other. There were 16 left-sided foci: 4 distal coronary sinus (CS dist), 3 pulmonary vein (PV), 3 septal, 3 mitral annulus, 3 other. "Other" category means antero-superior and lateral wall. The right- or left-sided origin of one septal focus could not be determined. In 3 procedures two distinct foci were found and ablated. There was no significant difference regarding the localization of ectopic foci between the two compared groups (Fig. 2). The distribution of the localizations is congruent with the previously published data $(2,6,13,16,24,31)$.

\section{Ablation procedure}

Out of the 60 ablation procedures 30 were mapped with conventional methods only whereas in another 30 cases CARTO electroanatomical mapping system was used as well. Additional supraventricular tachycardias were found and ablated in 6 cases (Table I). Moreover FAT was a secondary finding where atrial flutter was considered as clinical arrhythmia in two cases. Most of the focal atrial tachycardias were paroxysmal but 11 incessant cases occurred as well (6 of them were ablated with CARTO mapping and 5 cases with conventional mapping alone). Acute success rate (Fig. 3) was significantly higher in procedures where CARTO mapping was used $(27 / 30,90 \%)$ compared to procedures guided with conventional mapping $(18 / 30,60 \%, p<0.01)$. Similar difference was observed in case of left sided foci: success in $8 / 8(100 \%)$ CARTO enhanced procedures compared to $3 / 6(50 \%)$ in conventionally mapped procedures, although this difference was statistically not significant. There was no statistically significant difference in the success rate depending on the operating physician or use of irrigated and non-irrigated ablation catheters. There was no significant difference between procedure time ( $139 \pm 59 \mathrm{vs} .96 \pm 44 \mathrm{~min}, p$ : ns) and fluoroscopy time (18 $\pm 12 \mathrm{vs} .11 \pm 6 \mathrm{~min}$, $p$ : ns) although procedures with CARTO mapping tended to be longer compared to conventional mapping. No procedure related complications occurred (Fig. 3). 
Table I. Baseline parameters of the studied population

\begin{tabular}{|c|c|c|c|}
\hline & Conventional mapping & CARTO mapping & Significance \\
\hline Number of patients & 30 & 24 & ns \\
\hline Female & 21 & 18 & $\mathrm{~ns}$ \\
\hline $\begin{array}{l}\text { Age (years, mean } \pm \mathrm{SD}) \\
(\text { min.-max.) }\end{array}$ & $\begin{array}{l}61 \pm 14 \\
(30-83)\end{array}$ & $\begin{array}{l}48 \pm 18 \\
(19-77)\end{array}$ & ns \\
\hline Hypertension & 8 & 13 & ns \\
\hline Diabetes mellitus & 4 & 5 & ns \\
\hline COPD & 3 & 3 & $\mathrm{~ns}$ \\
\hline Heart surgery & 3 & 2 & ns \\
\hline Ischaemic heart disease & 3 & 7 & $\mathrm{~ns}$ \\
\hline Valvulopathy & 4 & 3 & ns \\
\hline MI grade II-III & 3 & 1 & $\mathrm{~ns}$ \\
\hline TI grade II-III & 1 & 2 & ns \\
\hline $\begin{array}{l}\mathrm{EF}(\%, \text { mean } \pm \mathrm{SD}) \\
(\min .-\max .)\end{array}$ & $\begin{array}{l}53 \pm 12 \\
(25-70)\end{array}$ & $\begin{array}{l}57 \pm 12 \\
(26-76)\end{array}$ & $\mathrm{ns}$ \\
\hline $\begin{array}{l}\text { Left atrium }(\mathrm{mm}, \text { mean } \pm \mathrm{SD}) \\
(\mathrm{min} .-\max .)\end{array}$ & $\begin{array}{c}41 \pm 7 \\
(27-53)\end{array}$ & $\begin{array}{c}40 \pm 9 \\
(24-59)\end{array}$ & ns \\
\hline Right ventricle systolic pressure $>35 \mathrm{mmHg}$ & 4 & 1 & ns \\
\hline Other arrhythmia beside FAT & 2 & 6 & ns \\
\hline Atrial flutter & 1 & 3 & $\mathrm{~ns}$ \\
\hline AVNRT & 1 & 3 & $\mathrm{~ns}$ \\
\hline Antiarrhythmic drugs & 24 & 26 & ns \\
\hline Beta-blockers & 15 & 14 & $\mathrm{~ns}$ \\
\hline Amiodarone & 1 & 2 & ns \\
\hline Propafenone & 1 & 3 & $\mathrm{~ns}$ \\
\hline Sotalol & 1 & 0 & ns \\
\hline Verapamil & 2 & 1 & $\mathrm{~ns}$ \\
\hline Combination & 4 & 6 & ns \\
\hline
\end{tabular}

Abbreviations: AVNRT = atrioventricular-nodal reentrant tachycardia, COPD $=$ chronic obstructive pulmonary disease, $\mathrm{EF}=$ ejection fraction, $\mathrm{FAT}=$ focal atrial tachycardia, $\max .=$ maximum, $\min .=$ minimum, $\mathrm{mm}=$ millimeter, $\mathrm{ns}=$ non-significant, $\mathrm{MI}=$ mitral insufficiency, $\mathrm{SD}=$ standard deviation, $\mathrm{TI}=$ tricuspid insufficiency

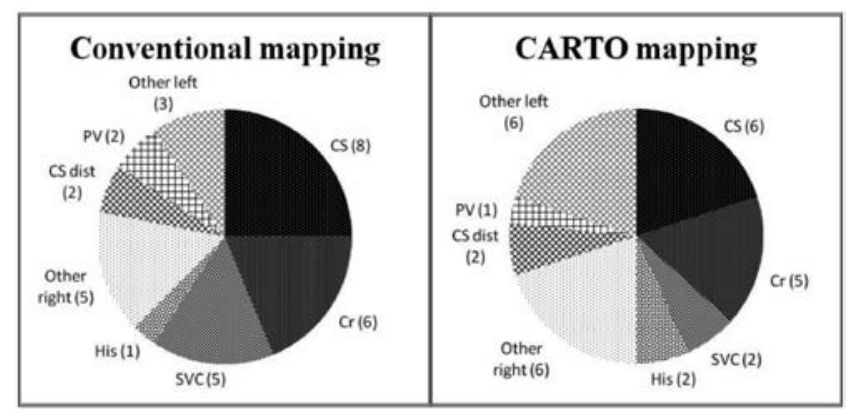

Fig. 2. Localization of ectopic foci in the conventional mapping (left side) and CARTO mapping (right side) procedures. Absolute numbers of ectopic foci are shown in parenthesis.

Abbreviations: $\mathrm{CS}=$ coronary sinus, $\mathrm{Cr}=$ crista terminalis, $\mathrm{SVC}=$ superior vena cava, His $=$ parahisian,

$\mathrm{CS}$ dist $=$ distal coronary sinus, $\mathrm{PV}=$ pulmonary vein. Other right and other left categories mean septal, tricuspid annulus, inferior vena cava, mitral annulus, antero-superior and lateral wall 


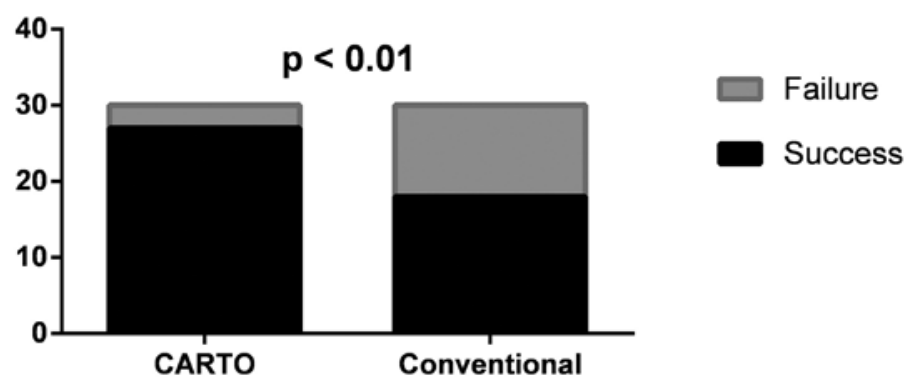

Fig. 3. Acute success rate of procedures

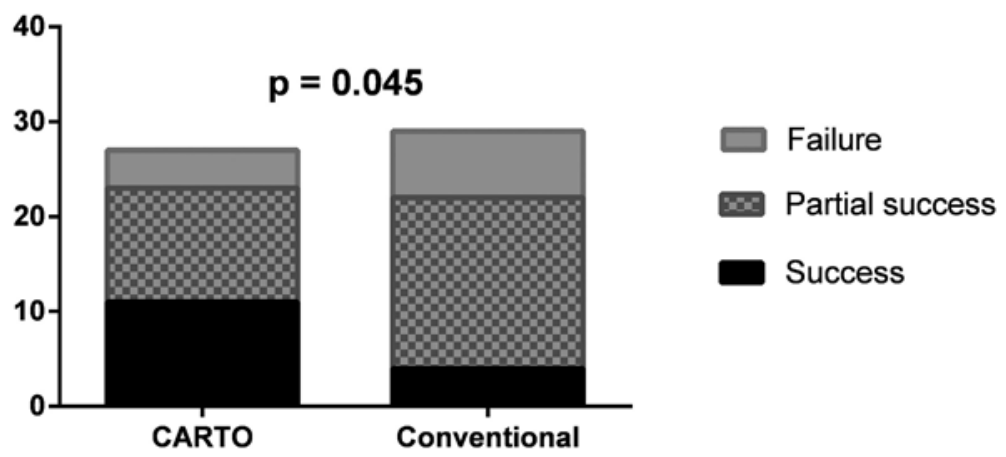

Fig. 4. Six-month success rate of procedures

\section{Follow-up}

The 6-month follow-up data were available in 56 cases ( 2 patients were foreign and 2 patients died). Patients remained free of FAT (success) in 11 cases after CARTO enhanced procedures and in 4 cases after ablation with conventional mapping only. Partial success (12 vs. 18) and failure (4 vs. 7) occurred less often in cases with CARTO mapping compared to conventional mapping (Fig. 4). Better 6-month outcome was evident in cases where CARTO mapping was used compared to procedures by conventional mapping $(p=0.045)$. Full or partial success was found more often in CARTO mapped ( $85 \%)$ than in conventionally mapped $(75 \%)$ cases. Repeated ablation procedure was necessary in 6 cases (after 4 conventionally and 2 CARTO mapped procedures), all of them were successfully performed with CARTO mapping.

\section{Discussion}

To the best of our knowledge this is the first report directly comparing the additional value of CARTO electroanatomical mapping system over conventional mapping methods in the treatment of focal atrial tachycardias. In our consecutive patient population better acute success rate $(90 \%$ vs. $60 \%)$ and 6-month outcome ( $85 \%$ vs. $75 \%)$ was found in CARTO enhanced procedures compared to procedures with conventional mapping only $(4,13,15$, $23,29)$. 
The goal of the antiarrhythmic therapy in focal atrial tachycardia is the clinical efficacy, to reach a better quality of life when patient's symptoms decrease or disappear completely. Antiarrhythmic treatment of focal atrial tachycardia is usually difficult but catheter ablation has been shown to be effective in its treatment, partially in combination with pharmacological therapy. Radiofrequency catheter ablation is currently the first-line therapy in all symptomatic focal atrial tachycardia cases, especially when cardiac dysfunction develops $(4,23,24,30)$ (Table II).

Data of 13 papers reporting results of catheter ablation of focal atrial tachycardias are shown in Table II. Direct comparative data of acute and mid-term efficacy of conventional mapping and CARTO enhanced catheter ablation had not been reported previously. The assessment of procedural data shows that ablation of 67 patients with conventional mapping was immediately successful in $91 \%$ of cases and the mid- or long-term success rate was $88 \%$. On the other hand, 156 ablations guided by CARTO electroanatomical mapping provided $93 \%$ acute and $89 \%$ mid- or long-term success rate. A solid meta-analysis of the published data is not possible, mostly because of various clinical end-points, different follow-up periods, and lack of data. Some authors define mid- or long-term success as the absence of arrhythmia without AAD-s confirmed by Holter-monitoring. On the other hand, other publications use the criteria of "clinical success", which means that the patient is free of symptoms with or without antiarrhythmic medication.

Based on data of prior publications, conventional mapping can be still a beneficial choice to guide catheter ablation based on the high success rate and lower cost. Moreover, a comparison of data does not seem to show any difference between the efficacy of conventional mapping and CARTO-enhanced mapping strategies (Table II), although statistical analysis of these data was not possible. On the other hand, our data show the superiority of using CARTO electroanatomical mapping system in case of ablation of focal atrial tachycardias.

\section{Study limitations}

Our retrospective analysis shows that CARTO enhanced procedures are more effective than the conventional method alone, however the success rate of conventionally mapped procedures is lower than reported previously $(13,15,29,30)$. Moreover, the ablation strategy was selected individually by the operating physician, was not randomized, which makes the theoretical possibility to quit conventional ablation and plan a second CARTO based procedure in difficult cases. However, one has to be aware of the fact that only 2 patients had a CARTO based ablation after an acute unsuccessful conventionally mapped procedure, so these treatment decisions do not alter our main findings significantly.

\section{Conclusions}

CARTO electroanatomical mapping system is a safe and effective method to guide catheter ablation of focal atrial tachycardia. Acute and mid-term clinical results seem to be superior in case of CARTO electroanatomical mapping compared to conventional mapping in our dataset. Therefore CARTO guided ablation seems to be more appropriate as initial ablation strategy in case of focal atrial tachycardia. 


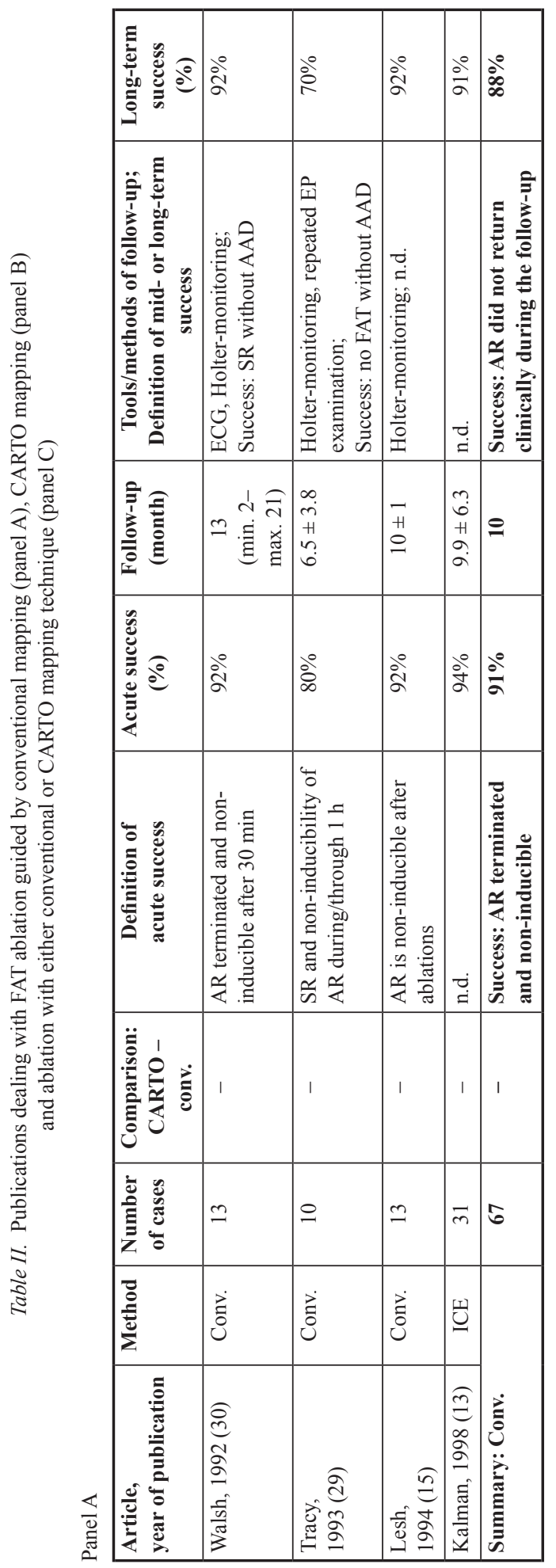

\begin{tabular}{|c|c|c|c|c|}
\hline 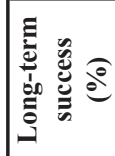 & ڤัे & ఏूे & ڤે̀ & 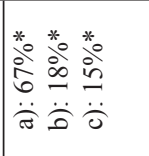 \\
\hline 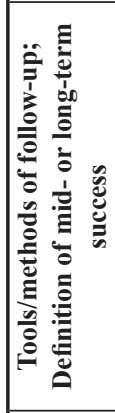 & $\underset{\dot{\Xi}}{\dot{=}}$ & 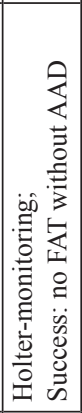 & 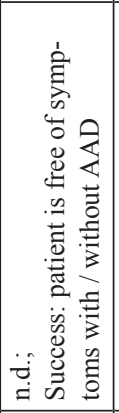 & 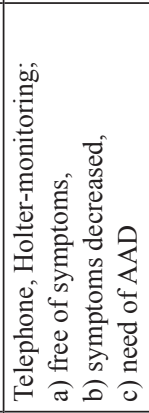 \\
\hline 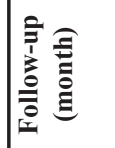 & $\underset{\ddot{\Xi}}{\ddot{\Xi}}$ & 6 & 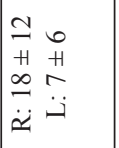 & 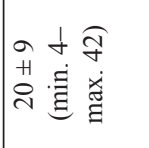 \\
\hline 遶 & ఏి̊ & ळें & 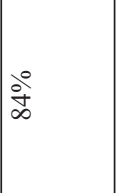 & ఓે \\
\hline 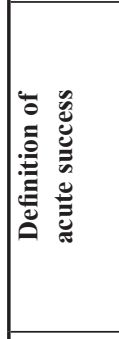 & $\overrightarrow{\dot{\Xi}}$ & 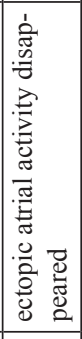 & 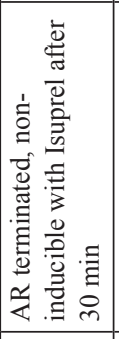 & 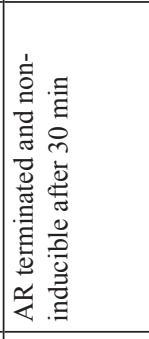 \\
\hline 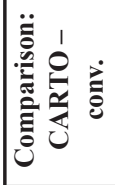 & & 1 & 1 & 1 \\
\hline 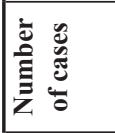 & ¿ & 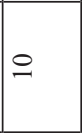 & 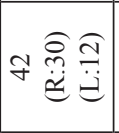 & 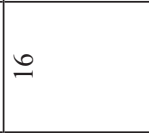 \\
\hline हूँّ & 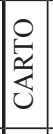 & 隹 & 官 & 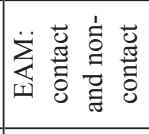 \\
\hline 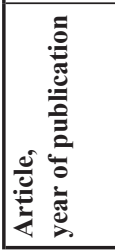 & 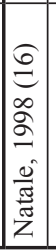 & 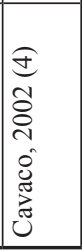 & 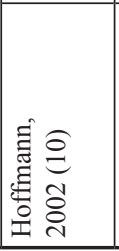 & 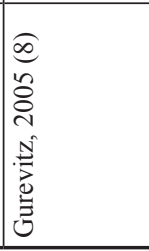 \\
\hline
\end{tabular}




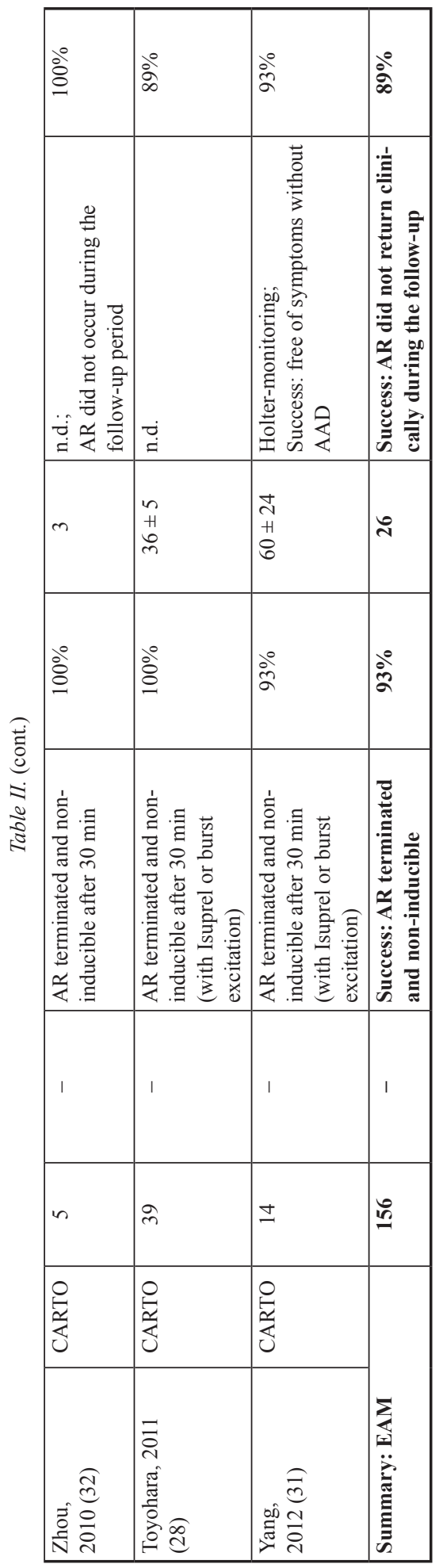

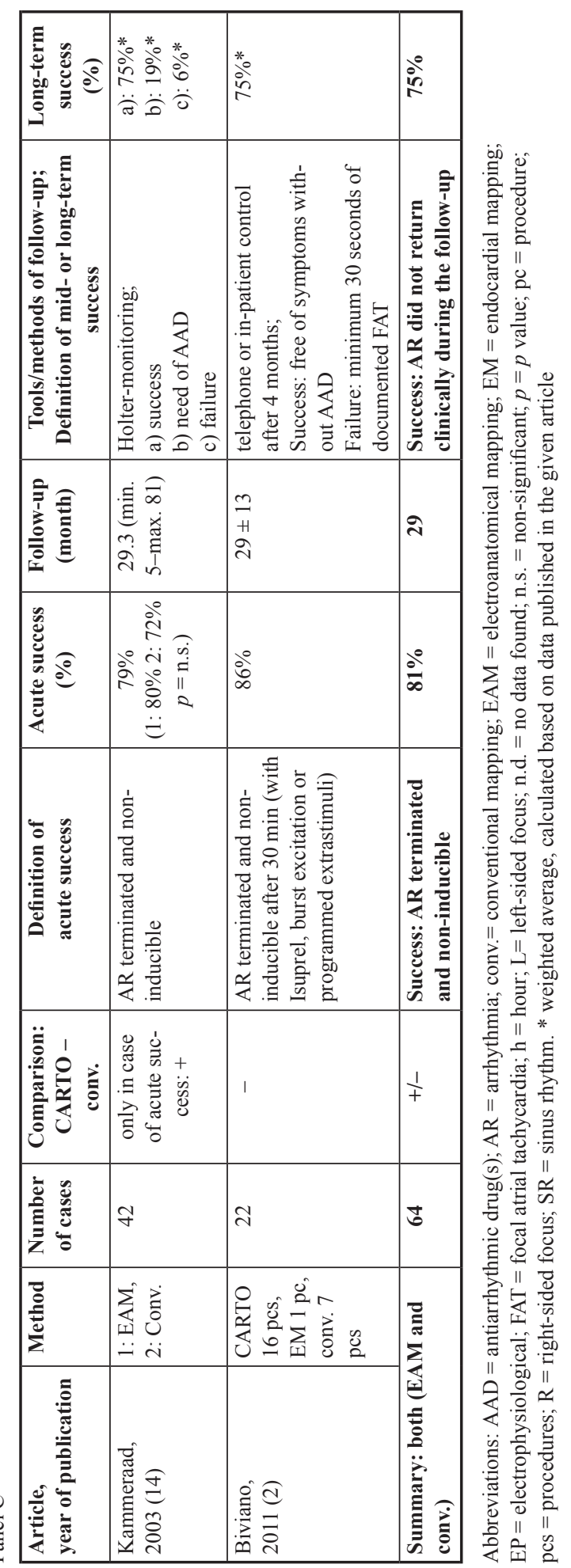




\section{REFERENCES}

1. Anguera I, Brugada J, Roba M, Mont L, Aguinaga L, Geelen P, Brugada P: Outcomes after radiofrequency catheter ablation of atrial tachycardia. Am. J. Cardiol. 87, 886-890 (2001)

2. Biviano AB, Bain W, Whang W, Leitner J, Dizon J, Hickey K, Garan H.: Focal left atrial Tachycardias not Associated with prior catheter ablation for atrial fibrillation: clinical and Electrophysiological characteristics. Pacing Clin. Electrophysiol. 35, 17-27 (2011)

3. Blomström-Lundqvist C, Scheinman MM, Aliot EM, Alpert JS, Calkins H, Camm AJ, Campbell WB, Haines DE, Kuck KH, Lerman BB, Miller DD, Shaeffer CW Jr, Stevenson WG, Tomaselli GF, Antman EM, Smith SC Jr, Alpert JS, Faxon DP, Fuster V, Gibbons RJ, Gregoratos G, Hiratzka LF, Hunt SA, Jacobs AK, Russell RO Jr, Priori SG, Blanc JJ, Budaj A, Burgos EF, Cowie M, Deckers JW, Garcia MA, Klein WW, Lekakis J, Lindahl B, Mazzotta G, Morais JC, Oto A, Smiseth O, Trappe HJ: ACC/AHA/ESC guidelines for the management of patients with supraventricular arrhythmias- executive summary. Eur. Heart J. 24, 1857-1897 (2003)

4. Cavaco D, Adragão P, Morgado F, Aguiar C, Chotalal D, Palos J, Bonhorst D, Seabra-Comes R: Electroanatomical mapping and ablation of atrial tachycardias with the CARTO system. Rev. Port. Cardiol. 21, 407-418 (2002)

5. Femenía F, Arce M, Arrieta M, Baranchuk A: (Taquicardia auricular focal incesante originada en la orejuela derecha: riesgo de taquicardiomiopatía. Rol de la ablación por radiofrecuencia.) Incessant focal atrial tachycardia arising from the right appendage: risk of tachycardia mediated cardiomyopathy. Role of the radiofrequency ablation. Arch. Argent. Pediatr. 109, 33-38 (2011)

6. Furushima H, Chinushi M, Hosaka Y, Aizawa Y: Focal atrial tachycardia refractory to radiofrequency catheter ablation originating from right atrial appendage. Europace 11, 521-522 (2009).

7. González-Torrecilla E, Arenal Á, Quiles J, Atienza F, Jiménez-Candil J, del Castillo S, Almendral J: Nonfluoroscopic electroanatomical mapping (CARTO System) in the ablation of atrial tachycardias. Rev. Esp. Cardiol. 57, 37-44 (2004)

8. Gurevitz OT, Glikson M, Asirvatham S, Kester TA, Grice SK, Munger TM, Rea RF, Shen WK, Jahangir A, Packer DL, Hammill SC, Friedman PA: Use of advanced mapping systems to guide ablation in complex cases: experience with noncontact mapping and electroanatomic mapping systems. Pacing Clin. Electrophysiol. 28, 316-323 (2005)

9. Hindricks G: The Multicentre European Radiofrekvency Survey (MERFS): Complications of radiofrequency catheter ablation of arrhythmias. Eur. Heart J. 14, 1644-1653 (1993)

10. Hoffmann E, Reithmann C, Nimmermann P: Clinical experience with electroanatomic mapping of ectopic atrial tachycardia. Pacing Clin. Electrophysiol. 25, 49-56 (2002)

11. Huo Y, Braunschweig F, Gaspar T, Richter S, Schönbauer R, Sommer P, Arya A, Rolf S, Bollmann A, Hindricks G, Piorkowski C: Diagnosis of atrial tachycardias originating from the lower right atrium: importance of P-wave morphology in the precordial leads V3-V6. Europace 4, 570-577 (2011)

12. Issa ZF, Miller JM, Zipes DP (2012): Focal atrial tachycardia. In: Clinical Arrhythmology and Electrophysiology. A companion to Braunwald's Heart Disease, 2nd edition, Philadelphia, Saunders, pp. 212-237

13. Kalman JM, Olgin JE, Karch MR, Hamdan M, Lee RJ, Lesh MD: “Cristal Tachycardias": Origin of right atrial tachycardias from the crista terminalis identified by intracardiac echocardiography. J. Am. Coll. Cardiol. 31, 451-459 (1998)

14. Kammeraad JAE, Balaji S, Oliver RP, Chugh SS, Halperin BD, Kron J, McAnulty JH: Nonautomatic focal atrial tachycardia: characterization and ablation of a poorly understood arrhythmia in 38 patients. Pacing Clin. Electrophysiol. 26, 736-742 (2003)

15. Lesh MD, Van Hare GF, Epstein LM, Fitzpatrick AP, Scheinman MM, Lee RJ, Kwasman MA, Grogin HR, Griffin JC: Radiofrequency catheter ablation of atrial arrhythmias: results and mechanisms. Circulation 89, 1074-1089 (1994)

16. Natale A, Breeding L, Tomassoni G, Rajkovich K, Richey M, Beheiry S, Martinez K, Cromwell L, Wides B, Leonelli F: Ablation of right and left ectopic atrial tachycardias using a three-dimensional nonfluoroscopic mapping system. Am. J. Cardiol. 82, 989-992 (1998)

17. Packer DL: Three-dimensional mapping in interventional electrophysiology: techniques and technology. J. Cardiovasc. Electrophysiol. 16, 1110-1116 (2005)

18. Poty H, Saoudi N, Haissaguerre M, Daou A, Clémenty J, Letac B: Radiofrequency catheter ablation of atrial tachycardias. Am. Heart J. 131, 481-489 (1996)

19. Poutiainen AM, Koistinen MJ, Airaksinen KEJ, Hartikainen EK, Kettunen RVJ, Karjalainen JE, Huikuri HV: Prevalence and natural course of ectopic atrial tachycardia. Eur. Heart J. 20, 694-700 (1999) 
20. Qian ZY, Hou XF, Xu DJ, Yang B, Chen ML, Chen C, Zhang FX, Shan QJ, Cao KJ, Zou JG: An algorithm to predict the site of origin of focal atrial tachycardia. Pacing Clin. Electrophysiol. 34, 414-421 (2011)

21. Reithmann C, Hoffmann E, Dorwarth U, Remp T, Steinbeck G: Electroanatomical mapping for visualization of atrial activation in patients with incisional atrial tachycardias. Eur. Heart J. 22, 237-246 (2001)

22. Roberts-Thomson KC, Kistler PM, Kalman JM: Focal atrial tachycardia I: clinical features, diagnosis, mechanisms, and anatomic location. Pacing Clin. Electrophysiol. 29, 643-652 (2006)

23. Roberts-Thomson KC, Kistler PM, Kalman JM: Focal atrial tachycardia II: management. Pacing Clin. Electrophysiol. 29, 769-778 (2006)

24. Rosso R, Kistler PM: Focal atrial tachycardia. Heart 96, 181-185 (2006)

25. Schmitt H, Weber S, Schwab JO, Voss RM, Kneller R, Tillmanns H, Waldecker B: Diagnosis and ablation of focal right atrial tachycardia using a new high-resolution, non-contact mapping system. Am. J. Cardiol. 87, 1017-1021 (2001)

26. Steinbeck G, Hoffmann E: 'True’ atrial tachycardia. Eur. Heart J. 19, E10-2, E48-9 (1998)

27. Teh AW, Kistler PM, Kalman JM: Using the 12-lead ECG to localize the origin of ventricular and atrial tachycardias: Part 1. Focal atrial tachycardia. J. Cardiovasc. Electrophysiol. 20, 706-709 (2009)

28. Toyohara K, Fukuhara H, Yoshimoto J, Ozaki N, Nakamura Y: Electrophysiologic studies and radiofrequency catheter ablation of ectopic atrial tachycardia in children. Pediatr. Cardiol. 32, 40-46 (2011)

29. Tracy CM, Swartz JF, Fletcher RD, Hoops HG, Solomon AJ, Karasik PE, Mukherjee D: Radiofrequency catheter ablation of ectopic atrial tachycardia using paced activation sequence mapping. J. Am. Coll. Cardiol. 21, 910-917 (1993)

30. Walsh EP, Saul JP, Hulse JE, Rhodes LA, Hordof AJ, Mayer JE, Lock JE: Transcatheter ablation of ectopic atrial tachycardia in young patients using radiofrequency current. Circulation 86, 1138-1146 (1992)

31. Yang Q, Ma J, Zhang S, Hu JQ, Liao ZL: Focal atrial tachycardia originating from the distal portion of the left atrial appendage: characteristics and long-term outcomes of radiofrequency ablation. Europace 14, 254-260 (2012)

32. Zhou YF, Wang Y, Zeng YJ, Li XL, Zheng JG, Yang P, Zhao X, Liu XF, Gao YS, Zhang H, Peng WH: Electrophysiologic characteristics and radiofrequency ablation of focal atrial tachycardia arising from noncoronary sinuses of Valsalva in the aorta. J. Interv. Card. Electrophysiol. 28, 147-151 (2010) 